\title{
AS CONCEPÇÕES DE ESSÊNCIA E EXISTÊNCIA EM DESCARTES E SARTRE
}

\author{
$\underline{\text { Naama Enéas da Silva Almeida }}{ }^{1}$; José Portugal dos Santos Ramos ${ }^{2}$ \\ 1. Bolsista PROBIC/CNPq, Graduanda em Psicologia, Universidade Estadual de Feira de Santana, e-mail: \\ naama_eneas@hotmail.com \\ 2. Orientador, Departamento de Ciências Humanas e Filosofia, Universidade Estadual de Feira de Santana, e-mail: \\ domluso@gamil.com
}

PALAVRAS-CHAVE: Descartes; Sartre; existência.

\section{INTRODUÇÃO}

Esta pesquisa teve como objetivo geral apresentar uma comparação entre as concepções de existência e essência em Descartes e Sartre a partir de seus sistemas filosóficos. Os objetivos específicos consistiram em: esclarecer as concepções de homem em Descartes e Sartre a partir das noções de essência e existência; explicitar os diferentes argumentos utilizados pelo autores trabalhados no que concerne aos meios pelos quais eles tratam as noções de essência e existência, a saber, o argumento da Filosofia Primeira (Metafísica) em Descartes e a Ontologia Fenomenológica em Sartre; e, por fim, evidenciar os desdobramentos que a opção sartriana por uma ontologia fenomenológica implica, abordando conceitos como náusea e angustia.

\section{MATERIAL E MÉTODOS OU METODOLOGIA (ou equivalente)}

A execução desta pesquisa não necessitou de recursos financeiros, sendo seu método completamente teórico. Os materiais bibliográficos utilizados foram adquiridos na biblioteca da própria instituição ou fornecidos pelo orientador da pesquisa Prof. Dr. José Portugal dos Santos Ramos, tendo os encontros do grupo como local de reunião o NEF/UEFS.

\section{RESULTADOS E/OU DISCUSSÃO (ou Análise e discussão dos resultados)}

A concepção de essência e existência em Descartes diz respeito à sua própria concepção de substância. Tal concepção, por sua vez, origina-se a partir da sua Teoria das Distinções, a qual estabelece três diferentes tipologias: distinção real, de razão e modal. A distinção real, em Descartes, refere-se a duas ou mais substâncias e afirma a necessidade de distingui-las; como, por exemplo, a distinção entre o pensamento (res cogitans) e corpo (res extensa). Nesta perspectiva, Descartes diz: "[...] a [distinção] real encontra-se propriamente entre duas ou várias substâncias. Com isso, podemos concluir que duas substâncias são realmente distintas uma da outra pelo fato de podermos conceber clara e distintamente uma delas sem pensar na outra." (DESCARTES, Princípios da Filosofia, 2005). Por outro lado, a distinção de razão é responsável pela diferenciação entre atributo e substância, estabelecendo uma relação de implicação recíproca entre os aspectos distinguidos; ou seja, só se pode falar da substância levandose em conta o seu atributo e vice-versa. A distinção de razão distinguirá, portanto, pensamento de coisa pensante, assim como extensão de coisa extensa. 
Por fim, a distinção modal refere-se às maneiras de se expressar da substância, estando inclusas nesta tipologia as distinções entre substância e seus modos ou entre os modos de uma mesma substância. Portanto, figura e movimento são distinções modais da res extensa, assim como entendimento e vontade o são da res cogitans, configurando distintas maneiras pelas quais cada substância se expressa (Cf. DESCARTES, 2005).

Para Descartes, a essência diz respeito ao atributo e a existência à substância. No entanto, nota-se, em suas obras, certa simbiose entre as concepções de atributo e substância ou, em outras palavras, uma determinação entre essência e existência. No artigo intitulado "Cada substância tem um atributo principal: o da alma é o pensamento e o do corpo é a extensão", também do livro Princípios da Filosofia, Descartes explica:

[...] se bem que cada atributo seja suficiente para conhecermos a substância, no entanto, em cada uma há um atributo que constitui a sua natureza e a sua essência e do qual todos os outros atributos dependem. Assim, a extensão em comprimento, largura e altura, constitui a natureza da substância corporal, e o pensamento constitui a natureza da substância que pensa. Com isso, tudo quanto pode ser atribuído ao corpo pressupõe a extensão e não passa de dependência do que é extenso. Igualmente, todas as propriedades que encontramos na coisa pensante são diferentes maneiras de pensar. Por exemplo, não poderíamos conceber uma figura se não for uma coisa extensa, nem um movimento sem ser num espaço que é extenso; assim, a imaginação, o sentimento e a vontade dependem de tal maneira de uma coisa pensante que não os podemos conceber sem ela. (DESCARTES, 2005, p. 44-45)

Diante disso, Pierre Aubenque, no artigo A transformação cartesiana do conceito aristotélico de substância afirma que Descartes se diferencia da concepção aristotélica de substância por tratar da mesma a partir do seu atributo. Por isso, Aubenque diz: "A substância não é dita existir por si, mas somente na medida em que existe ao menos um atributo para designá-la." (Aubenque, 2002).

Isso significa que, na fillosofia cartesiana, apesar de a distinção de razão diferenciar atributo e substância, tal separação se dá apenas na via do raciocínio, não havendo distinção ontológica e real entre esses conceitos. Ou seja, em última instância, as concepções de atributo (pensamento) e substância (coisa pensante) em Descartes se equivalem assim como as de essência e existência.

Para se chegar à essência da substância que pensa, Descartes realiza o exercício da dúvida metódica, descrita pelo mencionado autor no Discurso do Método. Descartes:

[...] resolvi fingir que todas as coisas que haviam entrado em meus espírito não eram mais verdadeiras que as ilusões de meus sonhos. Mas logo atentei que, enquanto queria pensar assim que tudo era falso, era necessariamente preciso que eu, que o pensava, fosse alguma coisa. E, notando que esta verdade - penso, logo existo - era tão firme e tão certa que todas as mais extravagantes suposições dos cépticos não eram capazes de a abalar, julguei que podia admiti-la sem 
escrúpulo como o primeiro princípio da filosofia que buscava. (DESCARTES, 2001, p.38)

Deste modo, Descartes apresenta seu princípio primordial de ser "uma substância, cuja única essência ou natureza é pensar", natureza esta que foi concedida por Deus, via designação do conceito de perfeição.

Já no que se refere a existência, é nas Meditações que Descartes afirma o argumento necessário que assegura a existência da coisa pensante. Ao fazer juízos de que todas as coisas existentes são falsas, chega-se à conclusão de que o efeito da dúvida possui uma causa, a saber, o pensamento, o qual é inerente à substância pensante préexistente.

Sartre, por sua vez, entende que não existe um atributo ou essência inerente ao ser humano. Isto porque o autor destitui de sua filosofia tanto a noção metafísica de substância proposta na modernidade por Descartes quanto a ideia de Deus. De acordo com a ontologia fenomenológica proposta por Sartre em $\mathrm{O}$ Ser e $\mathrm{O} N a d a$, só podemos falar do ser humano, o qual é denominado para-si, em oposição ao em-si, sendo este definido como a plenitude do ser. Enquanto o em-si é e o é plenamente, o para-si é algo que quer ser, consistindo na consciência humana, a qual está sempre projetando-se para ser alguma coisa, mas que nada é.

Nesta perspectiva, o para-si é a negação do em-si na medida em que este pode ser entendido como o ser de acordo com o viés essencialista das filosofias metafísicas (tal como a de Descartes). Sendo assim, por ser nada, tudo que conheço e falo sobre o para-si terá o em-si como referencial. Este é, pois, o meio pelo qual Sartre trata a noção de existência, afastando-se da ontologia clássica por Descartes no que concerne à noção de essência.

\section{CONSIDERAÇÕES FINAIS (ou Conclusão)}

Portanto, evidencia-se que a descoberta do eu pensante em Descartes se dá através da via reflexiva, mais precisamente, através de uma consciência reflexiva. Além disso, a noção de homem é compreendida como substancial. Por outro lado, Sartre afirma o caráter intersubjetivo e transcendente da consciência humana, situando a alteridade em uma posição de destaque nesse processo.

A descoberta do "cogito, ergo sum" ou "je pense donc je suis" em Descartes demarca a base da construção da sua filosofia. Ao se perceber como uma coisa pensante capaz de tomar consciência de sua própria existência, Descartes inaugura não apenas a subjetividade moderna, mas também uma nova perspectiva de obter e ampliar o conhecimento, a saber, através da dúvida metódica. Tanto Descartes quanto Sartre colocam o indivíduo numa posição de destaque, seja através do cogito ou da consciência posicional, respectivamente. É indubitável que os autores mencionados inauguram novas concepções de homem, fundamentas em sistemas filosóficos distintos; contudo, evidencia-se em ambos os autores citados, a preponderância da existência no processo humano de descoberta - de si mesmo e do mundo. 


\section{REFERÊNCIAS}

AUBENQUE, P. 2002. La transformation cartésienne du concept aristotelicien de substance. Paris: Les Belles Lettres.

ALQUIÉ, Ferdinand. 1986. A Filosofia de Descartes. Tradução de Rodrigues Martins. Lisboa: Editorial Presença.

COTTINGHAM, John. 1985. Cartesian Trialism. Mind, New Series, vol. 94, $\mathrm{n}^{\circ} 374$ (abril), pp. 218-230.

DESCARTES, René. 1973. Meditações Metafísicas. São Paulo: Abril Cultura.

1996. Oeuvres de Descartes. Paris: Librairie Philosophique J. Vrin. 11 vol. Publiées par Charles Adam e Paul Tannery. 2001. Discurso do Método. São Paulo: Martins Fontes.

2004. Meditações sobre Filosofia Primeira. René Decartes; tradução: Fausto Castilho. Ed bilingue em latim e portugues - Campinas, SP: Editora da Unicamp.

2005. Princípios da Filosofia. São Paulo, Editora Rideel.

GARBER, Daniel. 2001. Descartes and Occasionalism. In: Descartes Embodied: reading Cartesian philosophy through Cartesian science. Cambridge: Cambridge University Press, p. 203-220

GUEROULT, Martial. 1968. Descartes Selon L'Ordre des Raisons. Paris: Aubier. I e II. SARTRE. J.P. 1995. Esquisse d'une théorie des émotions. Paris: Hermann. 2014. O existencialismo é um humanismo. Petrópolis, RJ: Vozes. 2014. O ser e o nada. Petrópolis, RJ: Vozes. 